\section{Antagonism between Basic Compounds (Spermine, Streptomycin) and Basic Bactericidal Substances}

THE following bactericidal substances-trypa. flavine $\left(5 \times 10^{-4} M\right)$, methylene blue $\left(1 \times 10^{-3} M\right)$, protamine sulphate $\left(2.5 \times 10^{-4} M\right)$, chinine $(2.5 \times$ $\left.10^{-3}\right)$ and crystal violet $\left(1 \times 10^{-4} M\right)$-cause a strong and progressive inhibition of the respiration of bakers' yeast, suspended in glucose phosphate at $28^{\circ} \mathrm{C}$. (cf. also ref. 1). Spermine and streptomycin, though also basic substances, even at high concentrations $\left(1 \times 10^{-2} M\right.$ and $1 \times 10^{-2} M$ respectively) do not affect the respiration of yeast and thus have no direct bactericidal activity. It can be shown that all these substances, the inhibitors as well as spermine and streptomycine, compete for the same negative components of the yeast cell, when brought in contact with a yeast suspension ${ }^{2}$.

According to Dubos ${ }^{3}$ bactericidal substances such as basic dyes owe their bactericidal activity to two properties: the basicity or positive charge of the cation and the relatively large molecular weight, favouring the formation of sparingly soluble and feebly ionized compounds with negatively charged components of the bacterial cells.

Since all the substances we used are basic and have high molecular weight (protamine sulphate) or a relatively high molecular weight (spermine, trypaflavine, methylene blue, chinine, streptomycin, crystal violet), one wonders why some of these substances show a direct bactericidal activity and others not, the more that we have proved that they all compete for the same components of the bacterial cell ${ }^{2}$. Which is the property that the bactericidal substances possess and that spermine and streptomycin do not share?

It seems to us that a property deseribed by Michaelis ${ }^{4}$ for the basic dyes should be taken into account, namely, the occurrence of dimers, trimers and polymers in solutions of those substances. This polymerization is dependent upon the concentration. It is counteracted by the fact that these substances possess the same positive charge; but this aggregation or polymerization is, of course, favoured when the positive charges are held by negative components of the cell. It is evident that polymerization increases the effective molecular weight.

Why should we not admit that basic substances will show direct bactericidal activity when possessing a real high molecular weight, as is the case for protamine sulphate, or achieve a high molecular weight at definite concentrations by aggregation of their organic residues, the positive charges (cause of repulsion) being held by negatively charged components of the cells? This would be the case for methylene blue, trypaflavine, chinine and crystal violet, but not for spermine and streptomycin.

It might be expected that streptomycin and spermine, competing by virtue of their basicity with the bactericidal substances, but not being toxic, would be able to counteract the inhibition of respiration caused by these last substances. We have proved now that this is really the case : spermine at definite concentrations completely reverses the inhibition of respiration caused by trypaflavine, methylene blue, chinine, crystal violet and protamine; for example, in the presence of $2 \times 10^{-4} M$ spermine, trypaflavine $\left(2 \times 10^{-4} M\right)$ does not cause any inhibition under the conditions of our experiments. For streptomycin we were obliged to limit our observations to methylene blue and trypaflavine, but here, too, the reversal was complete; thus in the presence of $1 \times 10^{-3} M$ streptomycin, methylene blue $\left(1 \times 10^{-3} M\right)$ leaves the respiration of bakers' yeast untouched. Our experiments with spermine recall those of Silverman and Evans $^{5}$, who found that the toxic effect of atebrine upon the growth of $E$. coli is antagonized by spermine and other naturally occurring amines, but these authors postulated a growth-factor activity of these amines.

All our experiments were made at $28^{\circ} \mathrm{C}$. by means of the Warburg apparatus, with yeast suspensions in glucose-phosphate medium (10 mgm. fresh bakers' yeast in a final volume of $2 \mathrm{ml}$.).

Full experimental details will be published in Archives internationales de Pharmacodynamie et de Therapie.

We are indebted for several of the compounds used (spermine, clupeine sulphate) to the firm of Hofman. Laroche (Basle).

Biochemical Laboratory,

L. MassarT

Biochemical Centre,

University of Ghent. June 21.

${ }^{1}$ Massart, L., Peeters, G., De Ley, J., and Vercauteren, R., Experientia, 8, 119 (1947). 'De Ley, J., Peeters, G., and Massart, L. Biochim. et Biophys. Acta, 1, 393 (1947).

'Massart, L., Peeters, G., and Van Houcke, A., Experientia, 8, 280 (1947).

${ }^{3}$ Dubos, P., "The Bacterial Cell", 288 (Harvard University Press, 1947).

"Michaelis, L., Cold Spring Harbor Symposia, 10, 131 (1947).

silverman, M., and Evans, E. A., Jun., J. Biol. Chem., 150, 267 (1943).

\section{Structure of the Antibacterial Compound, Aspergillic Acid}

REDUC'ION of aspergillic acid, $\mathrm{C}_{12} \mathrm{H}_{20} \mathrm{O}_{2} \mathrm{~N}_{2}$, an antibiotic isolated from culture filtrates of Aspergillus flavus $^{1}$, gives in high yield a neutral reaction product, deoxyaspergillic acid, $\mathrm{C}_{12} \mathrm{H}_{20} \mathrm{ON}_{2}$, to which the structure 2-hydroxy-3:6-disec.-butylpyrazine has been ascribed ${ }^{2}$. We have previously described syntheses of 2-hydroxy-3:6-disec.-butylpyrazine ${ }^{8}$, and although we were unable to resolve the racemic compound, a comparison of its properties with those of deoxyaspergillic acid led us to conclude that the latter is a hydroxypyrazine derivative. Substantial differences in the intensity of light absorption in the ultra-violet, however, suggested that the two compounds differ more profoundly than in stereochemical orientation. Moreover, deoxyaspergillic acid has been racemized by treatment with alkali, and the racemate is distinct from 2 -hydroxy-3:6-disec.-butylpyrazine, which is itself unaffected by similar treatment with alkali.

Treatment of aspergillic acid with bromine followed by reduction of the bromo-substitution product with zinc and acetic acid gives a product, $\mathrm{C}_{12} \mathrm{H}_{22} \mathrm{O}_{2} \mathrm{~N}_{2}$. We find that hydrolysis of the compound $\mathrm{C}_{12} \mathrm{H}_{22} \mathrm{O}_{2} \mathrm{~N}_{2}$ with hydrobromic acid gives a mixture of two $\alpha$-amino-acids. Separation of the component $\alpha$ amino-acids was achieved by fractional solution of<smiles>CCN(CCC(C)C)C(=O)O</smiles><smiles>[R16]C([14CH3])[C@H](N)C(=O)O</smiles> 